\title{
Generalized Epilepsy
}

National Cancer Institute

\section{Source}

National Cancer Institute. Generalized Epilepsy. NCI Thesaurus. Code C3021.

A chronic condition characterised by recurrent generalised seizures. 